Portland State University

PDXScholar

\title{
Escherichia Coli Fpg Glycosylase is Nonrendundant and Required for the Rapid Global Repair of Oxidized Purine and Pyrimidine Damage In Vivo
}

\author{
Brandy J. Schalow \\ Portland State University \\ Charmain T. Courcelle \\ Portland State University \\ Justin Courcelle \\ Portland State University, justc@pdx.edu
}

Follow this and additional works at: https://pdxscholar.library.pdx.edu/bio_fac

Part of the Biology Commons, and the Cell Biology Commons

Let us know how access to this document benefits you.

\section{Citation Details}

Schalow, Brandy J.; Courcelle, Charmain T.; and Courcelle, Justin, "Escherichia Coli Fpg Glycosylase is Nonrendundant and Required for the Rapid Global Repair of Oxidized Purine and Pyrimidine Damage In Vivo" (2011). Biology Faculty Publications and Presentations. 100.

https://pdxscholar.library.pdx.edu/bio_fac/100

This Post-Print is brought to you for free and open access. It has been accepted for inclusion in Biology Faculty Publications and Presentations by an authorized administrator of PDXScholar. Please contact us if we can make this document more accessible: pdxscholar@pdx.edu. 


\title{
Escherichia Coli Fpg Glycosylase is Nonrendundant and Required for the Rapid Global Repair of Oxidized Purine and Pyrimidine Damage In Vivo
}

\author{
Brandy J. Schalow, Charmain T Courcelle, and Justin Courcelle \\ Department of Biology, Portland State University; PO Box 751 Portland OR, 97207
}

\begin{abstract}
Endonuclease III (Endo III) and Formamidopyrimidine-N-glycosylase (Fpg) are two of the predominant DNA glycosylases in E. coli that remove oxidative base damage. In cell extracts and purified form, Endo III is generally more active on oxidized pyrimidines, while Fpg is more active towards oxidized purines. However, the substrate specificities of these enzymes partially overlap in vitro. Less is known about the relative contribution of these enzymes in restoring the genomic template following oxidative damage. In this study, we examined how efficiently Endo III and Fpg repair their oxidative substrates in vivo following treatment with hydrogen peroxide. We found that Fpg was nonredundant and required to rapidly remove its substrate lesions on the chromosome. In addition, Fpg also repaired a significant portion of the lesions recognized by Endo III, suggesting that it plays a prominent role in the global repair of both purine and pyrimidine damage in vivo. By comparison, Endo III did not affect the repair rate of Fpg substrates and was only responsible for repairing a subset of its own substrate lesions in vivo. The absence of Endo VIII or nucleotide excision repair did not significantly affect the global repair of either Fpg or Endo III substrates in vivo. Surprisingly, replication recovered after oxidative DNA damage in all mutants examined, even when lesions persisted in the DNA, suggesting the presence of an efficient mechanism to process or overcome oxidative damage encountered during replication.
\end{abstract}

\section{Keywords}

oxidative damage; Fpg; Endonuclease III; Endonuclease VIII; DNA repair

\section{Introduction}

DNA damage caused by both endogenous and exogenous sources of reactive oxygen species is thought to be a primary event in the etiology of cancer and aging in humans. Reactive oxygen species induce a broad spectrum of distinct base modifications in DNA (reviewed in ${ }^{1}$ ). These lesions range from those that retain their coding specificities (dihydrothymine), to those that mis-pair during replication or transcription (8-oxoguanine), to those that block DNA and RNA polymerases and are potentially lethal (thymine glycol) ${ }^{2-4}$. In both E. coli and humans, oxidized base damage is predominantly removed by the base excision repair (BER) pathway in which a DNA glycosylase cleaves the glycosidic bond to release the damaged base. The sugar-phosphate backbone of the resulting apurinic or apyrimidinic (AP)

\footnotetext{
Address correspondence to: Brandy Schalow fax: 503-725-3888; brans@pdx.edu.

Publisher's Disclaimer: This is a PDF file of an unedited manuscript that has been accepted for publication. As a service to our customers we are providing this early version of the manuscript. The manuscript will undergo copyediting, typesetting, and review of the resulting proof before it is published in its final citable form. Please note that during the production process errors may be discovered which could affect the content, and all legal disclaimers that apply to the journal pertain.
} 
site is then incised by an AP endonuclease and sometimes processed before a new nucleotide is polymerized and the DNA strand is religated by polymerase I and ligase (reviewed in ${ }^{5}$ ).

To deal with the range of base modifications formed by reactive oxygen species, organisms contain a suite of evolutionarily conserved glycosylases that are involved in the initial step of BER (reviewed in ${ }^{6}$ ). In E. coli, Exonuclease III, Fpg, Uracil-DNA glycosylase, Endonucleases III, IV, V, and VIII are all involved in removing oxidized bases, while mammalian cells encode homologs, and in many cases multiple homologs, for each of these glycosylases ${ }^{6}$. In vitro, these glycosylases are capable of recognizing and removing a range of structurally related base modifications and, in many cases, their substrate specificities overlap significantly ${ }^{7-9}$. This, in addition to the observation that no single glycosylase mutant is hypsersensitive to oxidative damage, has led to the view that redundancies are likely to exist among glycosylases to remove most major forms of oxidative base damage in the cell ${ }^{7,9,10}$.

Based on their activity in cell extracts and in purified form, Fpg and Endo III are two of the primary activities that remove common forms of oxidative purines and pyrimidines, respectively ${ }^{11-14} . \mathrm{fpg}$ was initially identified as $\operatorname{mutM}$, a gene that reduced the frequency of $\mathrm{GC} \rightarrow \mathrm{TA}$ transversions ${ }^{15}$. In vitro, Fpg glycosylase efficiently recognizes a range of oxidized purines, including 8-oxoguanine and 4,6-diamino-5-formamidopyrimidine (FapyAde) lesions which are among the most abundant oxidized purines formed by free radical damage in vivo ${ }^{16-18}$. In addition, the enzyme is also active on some prominent forms of oxidized pyrimidine base damage, including 5-hydroxycytosine (5-OHC), 5-hydroxyuracil (5-OHU) and dihydrothymine ${ }^{19,20}$, but has little to no activity on other prominent pyrimidines such as thymine glycols ${ }^{11,19-21}$. Endo III was isolated as an enzyme that cleaves UV-irradiated DNA ${ }^{22}$. Purified Endo III recognizes and removes a range of modified pyrimidines, including thymine glycols, uracil glycols, 5-OHC, 5-OHU, and dihydrothymine $7,12,23$. Some weak activity towards the minor purine lesions, Fapy-Ade, guanidinohydantoin, and spiroimodihydantion has also been reported, but it does not appear to efficiently recognize other form of purine lesions ${ }^{23,23-25}$ (Fig 1).

Much of what we know about glycosylase function has been inferred from their substrate preferences and relative activities in purified form when incubated with oxidatively damaged DNA or oligos containing defined lesions. However, in a cellular context, some glycosylases may have specialized functions that couple their activity to processes such as transcription, replication, or cell division. Glycosylases may also be regulated spatially or temporally by protein partners which effectively limit their access to lesions in the overall genome. Finally, in some cases, specific lesions are known to be efficiently recognized by multiple glycosylases in vitro, leading to the question of whether functional specialization or redundancy between glycosylases occurs in vivo.

To gain a better understanding of the comparative activities of these enzymes in vivo, we measured the rate that Fpg and Endo III remove their respective substrates from the genome following hydrogen peroxide-induced DNA damage. We find that Fpg is nonredundant and is required to rapidly remove its own substrates from the chromosome in vivo as well as for a significant fraction of those recognized by Endo III. By comparison, the absence of Endo III had only a modest effect on the global repair rate of its substrate lesions in vivo, and neither Endo VIII nor nucleotide excision repair contributed to the rate of lesion removal within the time frame we examined. These observations are consistent with the known substrate specificities of Fpg and Endo III and indicate that Fpg plays a prominent role in the global repair of both purine and at least some pyrimidine lesions, in vivo. Despite the persistence of lesions in fpg mutants, replication was not prevented from recovering after 
oxidative damage, suggesting that the cell contains a uniquely efficient mechanism to process oxidized lesions that may be encountered during DNA replication.

\section{Results}

\section{Fpg and Endo III recognized lesions are rapidly repaired in vivo}

Although the overall range of substrates recognized by Fpg and Endo III partially overlaps, these enzymes exhibit distinct substrate preferences towards oxidized purines and oxidized pyrimidines, respectively $7,11,19,20,23$. To examine if these substrate preferences can be detected in our enzyme preparations, purified high molecular weight $E$. coli DNA was treated either with methylene blue plus white light or with osmium tetroxide. Previous studies have shown that treatment with methylene blue plus light generates primarily 8oxoguanines and Fapy-Gua lesions in DNA ${ }^{11,26}$. By contrast, treatment with osmium tetroxide generates almost exclusively thymine glycol lesions ${ }^{27}$. To monitor for the presence of lesions recognized by Fpg or Endo III glycosylases, DNA samples were incubated with each glycosylase and then electrophoresed through an alkali-agarose gel. Both Fpg and Endo III contain an associated AP-endolyase activity that nicks the DNA backbone following the removal of modified bases recognized by these enzymes 28,29 . Thus, the presence of lesions recognized by each glycosylase can be monitored by the loss of high molecular weight DNA in the glycosylase-treated samples. When Fpg glycosylase was incubated with DNA treated with methylene blue plus light, the DNA was incised or nicked much more extensively than it was after incubation with Endo III (Fig 2). The modest activity of Endo III towards methylene blue plus light-treated DNA may be due to the presence of Fapy-Gua, which Endo III has been reported to weakly recognize in vitro ${ }^{25}$. In contrast, when the osmium tetroxide-treated DNA was incubated with each of the glycosylases, the situation was reversed. Endo III incubation resulted in a loss of highmolecular-weight DNA whereas Fpg exhibited comparatively little activity towards the osmium tetroxide-treated DNA. Importantly, incubation of mock-treated DNA with either Fpg or Endo III resulted in little or no loss of high molecular weight DNA, demonstrating that the Fpg and Endo III activity was specific to the oxidative lesions formed by these treatments. Overall, the results are consistent with the known substrate specificities of these enzymes and demonstrate that differences in their preferred substrates can be detected using this type of assay.

To measure the repair of oxidative DNA lesions in vivo, cultures were treated with $10 \mathrm{mM}$ hydrogen peroxide for $5 \mathrm{~min}$, filtered to remove the chemical, and then resuspended in fresh pre-warmed media to recover. Total genomic DNA was then purified from the culture at 0 , 5, 10, 20 and $40 \mathrm{~min}$ after the hydrogen peroxide was removed. To determine how rapidly lesions recognized by Fpg and Endo III are removed from the chromosome in vivo, purified DNA from each time point was treated with either no glycosylase, Fpg glycosylase, or Endonuclease III, and then electrophoresed in a denaturing alkali agarose gel, as before.

In wild-type cultures, mock-treated genomic DNA remained high molecular weight at all time points examined, both before and after hydrogen peroxide exposure (Fig 3A). DNA fragments averaged greater than $40 \mathrm{~kb}$ in length, which was the approximate limit of resolution in our agarose gels. Incubation of the genomic DNA with Fpg glycosylase resulted in a loss of high molecular weight fragments at times immediately after hydrogen peroxide exposure, indicating that lesions recognized by Fpg were present in the DNA. The number of Fpg-recognized lesions in the DNA actually increased slightly during the first 5 min after hydrogen peroxide was removed from the medium. However, within $10 \mathrm{~min}$, the number of lesions recognized by Fpg in the DNA began to decrease and lesion-free high molecular weight fragments began to reappear. By 40 min, more than $80 \%$ of the high molecular weight DNA had been restored (Fig 3A). Repair could not be quantified at times 
beyond 40 min following hydrogen peroxide treatment due to the rapid recovery of DNA synthesis and accumulation of new DNA (see below and Fig 5).

Lesions recognized by Endo III were removed from the chromosome at a rate similar to lesions recognized by Fpg. Incubation of samples with Endo III resulted in a loss of high molecular weight fragments at times immediately following the removal of hydrogen peroxide. The number of enzyme-sensitive sites in the genomic DNA increased modestly during the first $5 \mathrm{~min}$ of the recovery period before lesion-free, highmolecular weight DNA fragments began to return. After 40 min, more than $80 \%$ of the high molecular weight fragments had been restored.

Importantly, no loss of high molecular weight DNA was observed following incubation of Fpg or Endo III with DNA from cells that were not exposed to hydrogen peroxide, indicating that glycosylase incision was due specifically to the presence of oxidized lesions recognized by these enzymes. To ensure that all potential substrates recognized by Fpg were incised, the highest concentration of glycosylase that remained specific for damaged DNA was used in all experiments (Fig S1). The alkali buffer in the agarose gels will cleave DNA at sites containing AP sites ${ }^{30}$. This, along with repair events initiated during the 5-min period in which the culture is exposed to hydrogen peroxide, is likely to account for the modest loss of high molecular weight DNA which averaged 30\% at times immediately after exposure to hydrogen peroxide in non-glycosylase-treated samples (see Fig 3, pretreated vs. 0 min and 5 min time points). To normalize for these nicks and AP-sites present in the purified DNA, the fraction of lesion-free DNA was normalized to the amount present in the mock-glycosylase-treated samples at each time point examined.

The observed increase in lesion frequency that occurs during the first 5 min of the recovery period is likely to be due to reactive oxygen species that continue to be generated in the cell after hydrogen peroxide has been removed ${ }^{31,32}$. The lesion frequency at any given time, as determined based on the average DNA fragment size in the enzyme-treated samples from at least three independent experiments, never exceeded more than one Fpg-substrate per $\sim 40$ $\mathrm{kb}$ strand of DNA or more than one Endo III-substrate per $\sim 20 \mathrm{~kb}$ strand of DNA. However, the continued induction of DNA lesions during the repair period makes it difficult to directly determine the total number of DNA lesions that were generated by this treatment.

Nevertheless, the observation that lesion-free, high molecular weight DNA was restored within $15 \mathrm{~min}$ of the time at which the maximum lesion frequency was observed indicates that both classes of these lesions are rapidly repaired in vivo.

\section{In vivo, Fpg is required for the rapid removal of its substrate lesions from the genome as well as for a significant portion of the lesions recognized by Endo III}

To examine how efficiently Fpg and Endo III function in the global repair of their respective lesions in vivo, we measured the rate at which their substrates were repaired in fpg and $n t h$ mutants. We reasoned that if a redundant glycosylase is present for each of the enzyme's substrates, then the repair rate would be unaffected when either Fpg or Endo III is absent in the cell. Alternatively, if functionally redundant activities for these substrates do not exist in vivo, then we would expect that the repair of lesions would be impaired in the absence of that glycosylase.

To this end, fpg-and $n t h$ - cultures were treated with hydrogen peroxide and at the indicated times, DNA was purified and analyzed as before. In contrast to wild-type cultures, lesions recognized by Fpg glycosylase persisted in the genomic DNA of fpg mutants throughout the recovery period. After 40 min, less than $30 \%$ of the high molecular weight DNA fragments had been restored. In addition, Fpg substrates accumulated at a higher frequency in $f p g$ mutants than wild-type cells, based on the average size of the DNA fragments in Fpg-treated 
samples (Fig 3B and C). This observation indicates that a functional redundancy does not exist to rapidly remove Fpg-recognized lesions from the overall genome in vivo.

Unexpectedly, a substantial portion of the lesions recognized by Endo III also persisted in the genome of $f p g$ mutants (Fig 3). Endo III-sensitive sites persisted in the genome of $f p g$ mutants throughout the 40-min recovery period and also accumulated to a higher frequency than in wild-type cells. Although Fpg is generally considered to repair purine-derived base damage, recent studies have shown that in vitro, Fpg recognizes several common forms of oxidized pyrimidines as efficiently as Endo III, including 5-OHC, 5-OHU, and to a lesser extent dihydrothymine ${ }^{12}$. We interpret this observation to indicate that although Fpg and Endo III are both capable of recognizing these lesions in vitro, Fpg is the primary enzyme that removes these substrates globally from the overall genome in vivo.

Consistent with this interpretation, a significant portion of Endo III substrates were still repaired in $n$th mutants which lack Endo III. Within $40 \mathrm{~min}, 50 \%$ of Endo III substrates had been removed from the genome in $n t h$ mutants, compared to $80 \%$ in wild-type cultures. The absence of Endo III had even less of an impact on the rate that Fpg-recognized lesions were repaired from the genome, consistent with in vitro studies that suggest that Endo III does not recognize the predominant Fpg substrates formed by hydrogen peroxide treatment ${ }^{12,25}$. In fpg nth double mutants, the repair rate of both Fpg substrates and Endo III substrates was impaired to an extent that was similar to that seen in the fpg single mutant.

The presence of Fpg did not completely complement repair in $n t h$ mutants, as a modest, but detectable, fraction of lesions persisted in the DNA (Fig 3, compare Endo III treated samples in $n$th mutants to WT). This population of lesions is likely to include, thymine glycols, which represent approximately $30 \%$ of the total lesions induced by hydrogen peroxide treatment ${ }^{33}$, and are known to be recognized by Endo III, but not Fpg, in vitro 7, 11, 19, 23 . Taken together, these experiments indicate that Fpg glycosylase is nonredundant and necessary for the rapid global repair of its substrate lesions as well as for a significant portion of the substrates that are recognized by Endo III.

\section{Endo VIII and Nucleotide Excision Repair do not detectably contribute to the removal of oxidized purines or pyrimidines in the overall genome}

Other enzymes have also been suggested to contribute to the repair of lesions recognized by Fpg and Endo III. In vitro, the substrate specificity of Endo VIII glycosylase, encoded by $n e i$, overlaps significantly with both Endo III and Fpg, recognizing the most abundant forms of oxidized purines and pyrimidines, 8-oxoguanine and thymine glycol, respectively ${ }^{8,34-36}$. In addition, UvrA, encoded by $u v r A$ and required for nucleotide excision repair, is also capable of recognizing thymine glycols in vitro ${ }^{37,38}$. To examine whether Endo VIII or nucleotide excision repair contributes to the removal of these lesions from the genome in vivo, we measured the repair of Fpg and Endo III substrates in nei and $u v r A$ mutants.

DNA was purified from hydrogen peroxide-treated nei or $u v r A$ cultures at various times during the recovery period, and the repair of Fpg- and Endo III-recognized lesions was analyzed as before. In cultures lacking Endo VIII, we observed that both Fpg- and Endo IIIrecognized lesions were repaired at rates similar to that observed in wild-type cultures (Fig 4). Similarly, $u v r A$ mutants removed these lesions at rates that were comparable to wild-type cultures (Fig 4). These data indicate that although Endo VIII and nucleotide excision repair are both capable of recognizing these lesions in vitro, they do not significantly contribute to the removal of these lesions from the overall genome. 


\section{The persistence of oxidative lesions in fpg mutants does not prevent replication from resuming}

More than $30 \%$ of the oxidized bases generated by hydrogen peroxide-treatment consist of thymine glycols and other lesions that are known to block DNA polymerases in vitro and in vivo $3,33,39$. Thus, one might expect that replication would be disrupted in cultures exposed to hydrogen peroxide and that the recovery of replication would be delayed in mutants where a significant amount of blocking lesions persist in the genome. Alternatively, it is possible that a repair or tolerance mechanism is specifically coupled to replication and is required to remove lesions encountered at the replication fork. Therefore, to examine whether the absence of Fpg, Endo III, Endo VIII, or nucleotide excision repair impair the cell's ability to replicate in the presence of oxidative damage, we monitored the recovery of DNA synthesis in these mutants following treatment with hydrogen peroxide. To this end, cultures grown in the presence ${ }^{3} \mathrm{H}$-thymine were either mock-treated or exposed to $10 \mathrm{mM}$ hydrogen peroxide for $5 \mathrm{~min}$, collected on filters and resuspended in fresh pre-warmed media supplemented with ${ }^{3} \mathrm{H}$-thymine. At the indicated times during and after hydrogen peroxide treatment, duplicate aliquots of culture were lysed and the DNA was precipitated. The amount of DNA that accumulated over time could then be followed by the amount of ${ }^{3} \mathrm{H}$ incorporated into the DNA. In wild-type cultures, a brief inhibition of replication was observed immediately following the period of exposure to hydrogen peroxide. However within $20 \mathrm{~min}$ after the hydrogen peroxide was removed, replication began to recover and the accumulation of DNA returned to a rate comparable to that of unexposed cultures (Fig $5 \mathrm{~A})$.

When we examined replication in fpg mutants, we observed that DNA replication resumed within 20 min of hydrogen peroxide removal and DNA began to accumulate at a rate that was comparable to wild-type cells. The resumption of replication was somewhat unexpected, considering that the oxidative lesions persist in the genome of these mutants, including those recognized by Endo III, and suggests that the cells may contain an efficient mechanism to either couple the repair to replication or tolerate these lesions.

When we examined the replication that occurred following exposure to hydrogen peroxide in cultures of $n t h$, nei, or $u v r A$ mutants, we observed that it was inhibited to a similar extent and duration as occurred in wild-type cultures. In each case, replication resumed at a time similar to that seen in wild-type cultures. Consistent with this observation and with previous reports, the absence of Fpg, Endo III, Endo VIII, or UvrA did not render cells hypersensitive to oxidative damage generated by hydrogen peroxide (Fig 5B) $7,10,40$. By contrast, and for the purposes of control, the viability of $r e c A$ cultures was reduced by approximately 4 orders of magnitude following a $5 \mathrm{~min}$ exposure to $10 \mathrm{mM}$ hydrogen peroxide. Taken together, the observations indicate that the absence of these repair enzymes does not prevent replication from resuming following the induction of oxidative DNA damage.

\section{Discussion}

Fpg and Endo III have sometimes been generalized as glycosylases that predominantly repair oxidized purine and pyrimidine damage, respectively $6,11,41,41,42$. However, recent biochemical studies have demonstrated that Fpg is also capable of recognizing some commonly formed oxidized pyrimidines as efficiently as Endo III including 5-OHC and 5$\mathrm{OHU}^{20}$. Similarly, Endo III has been reported to recognize at least one minor form of a purine-derived lesion, Fapy-Ade ${ }^{23}$. While, the substrates and efficiencies of these glycosylases have been characterized extensively in vitro, the relative contribution of each enzyme in repairing oxidative damage in vivo has not been examined directly. 
Here, we examined the efficiency with which Fpg and Endo III remove their respective substrate lesions from the chromosome. Our results indicate that Fpg is required for the rapid global repair of its substrates as well as a significant portion of the substrates recognized by Endo III. Endo III had a detectable but minor contribution to the repair of its own substrate lesions in vivo, and did not significantly contribute to the repair of Fpgrecognized lesions. Neither Endo VIII nor nucleotide excision repair, which have overlapping substrate specificites in vitro, detectably contributed to the repair of Fpg- or Endo III-recognized substrates in vivo. The persistence of Endo III substrates in fpg mutants, but less so in $n t h$ mutants, indicates that even though both Fpg and Endo III are equally capable of recognizing pyrimidine-derived lesions such as 5-OHC and 5-OHU in vitro, Fpg is the predominant activity that removes these lesions globally from the genome in vivo. Considering that Fapy-Ade is a relatively minor oxidative product and that Endo III has not been reported to recognize any other purine-derived lesions ${ }^{23}$, the observation that Endo III does not contribute to the repair of Fpg substrates in vivo would be consistent with its known substrates preferences in vitro. We would speculate that the modest portion of lesions that depend on Endo III for repair is likely to be made up of thymine glycols lesions, at least in part. Thymine glocols represent approximately $30 \%$ of the lesions generated by hydrogen peroxide treatment and are known substrates for Endo III, but not Fpg glycosylase $7,7,11,19,33$.

In vitro, the substrate specificities of oxidative glycosylases overlap significantly and no single glycosylase mutant is hypersensitive to oxidative challenges. In combination, these observations have sometimes been interpreted to suggest that significant redundancies exist among glycosylases to repair oxidative lesions $9,43,44$. The observed persistence of lesions in fpg mutants implies that significant redundancies are not present in this case at the level of glycosylase function. The rapid recovery of replication in these mutants, despite the persistence of the lesions implies that survival in these cells may depend on an efficient mechanism for repairing or tolerating oxidative lesions encountered that is coupled to replication. It remains possible that a specific glycosylase and/or translesion DNA polymerase efficiently removes or bypasses lesions encountered by the replication machinery ${ }^{45-48}$.

Elucidating which glycosylases, translesion DNA polymerases, or alternative enzyme allows replication to occur in the presence of oxidative damage is likely to require a detailed kinetic analysis of candidate mutants, both singly and in combination. Analogously, the mechanism by which replication recovers after UV-induced damage required an examination of mutliple mutants in combination. In this case, it has been shown that replication forks blocked by UV-induced damage are processed by RecJ and nucleotide excision repair. However, in the absence of any of these gene products, the recovery of synthesis still occurs but becomes dependant on translesion synthesis by DNA Polymerase V 49,50 . Under these conditions, although DNA Polymerase V prevents lethality and allows replication to resume, it occurs with slower kinetics and is associated with an elevated frequency of mutagenesis ${ }^{49-51}$. In support of this idea, eukaryotic DNA polymerase eta is capable of bypassing oxidative damage with limited efficiency, and some evidence suggests translesion DNA polymerases also participate in the bypass of oxidative lesions in E. coli ${ }^{45-48,52}$. Similarly, although no single glycosylase mutant is hypersensitive to oxidative damage, many double mutants such as nth nei exhibit high levels of mutagenesis ${ }^{8,10}$, perhaps suggesting that secondary mechansims are operating to allow recovery to occur under these conditions. 


\section{Materials and Methods}

\section{Bacterial strains}

Strains used in this study are summarized in Table 1. All strains are derived from SR108, a thyA36 deoC2 derivative of $\mathrm{W} 3110^{53}$. CL1005 (SR108 nei::cam) was constructed via P1 transduction of the nei::cam allele from SW2-8 into SR108 ${ }^{36}$. CL1006 (SR108 nth::kan) and CL1009 (SR108 fpg::amp) were constructed by P1 transduction of $n t h:: k a n$ and fpg::amp alleles from BW402 and SW2-F, respectively, into SR $108{ }^{8}$. The presence of the $f p g, n t h$, and $n e i$ alleles was confirmed by PCR. CL002 (SR108 recA::Tn10) and CL21 (uvrA::Tn10) have been previously described ${ }^{54,55}$.

CL1775 (DY351 fpg::tet) was constructed by gene replacement using recombineering strain DY $351^{56}$. The tetracycline resistance cassette was amplified from Tn 10 using fpgF primer 5'TAGCGTGCAGCGGCGGGCTAAATATCTGCTGCTGGAGCTGACTCGACATCTTG G TTACCG and fpgR primer 5'CTTTAATCACCCGAGCTAACAATTCACACTCTGCCAGCGACAAGAGGGTCATT AT ATTTCG. The PCR product was transformed into DY351 to generate CL1775, selecting for tetracycline resistance. The gene replacement was then moved into SR108 by standard P1 transduction, generating strain CL1778 (SR108 fpg::tet). CL1938 (SR108 nth::kan fpg::tet) was constructed by moving fpg::tet from CL1778 into CL1006 (SR108 nth::kan). Strains CL1778 and CL1938 were confirmed by selecting for tetracycline resistance and by PCR.

\section{Preparation of 8-oxoguanine and thymine glycol containing DNA}

To generate oxidized purine DNA, $5 \mu \mathrm{g}$ of high molecular weight $E$. coli DNA was treated with $1 \mu \mathrm{g} / \mathrm{ml}$ methylene blue (Acros Organics) and placed under a $100 \mathrm{~W}$ GE white light bulb for $5 \mathrm{~min}$ on ice ${ }^{26}$. Previous studies have shown this treatment genetrates 8-oxoguanine and Fapy lesions in a ratio of approximately 20:1. The DNA was then gently precipitated with an equal volume of isopropanol, washed in $70 \%$ ethanol and resuspended in TE (10 $\mathrm{mM}$ Tris, $1 \mathrm{mM}$ EDTA, $\mathrm{pH}$ 8.0). To generate oxidized pyrimidine DNA, $5 \mu \mathrm{g}$ of high molecular weight $E$. coli DNA was incubated in $0.4 \%$ osmium tetroxide (Acros Organics) for $1 \mathrm{hr}$ at $30^{\circ} \mathrm{C}$, adapted from ${ }^{27}$. The treated DNA was then extracted 4 times with chloroform to remove the osmium tetroxide and dialyzed against $200 \mathrm{ml}$ of TE for $1 \mathrm{hr}$.

\section{Hydrogen Peroxide Survival}

Fresh overnight cultures were diluted 1:100 and grown to an $\mathrm{OD}_{600}$ of 0.4 , (approximately $6 \times 10^{8}$ cells $/ \mathrm{ml}$ ) then treated with $10 \mathrm{mM}$ hydrogen peroxide (Fisher Scientific). At the times indicated, 0.1-ml aliquots of each culture were removed and serially diluted in 10-fold increments. Triplicate $10-\mu l$ aliquots of each dilution were then spotted on Luria Bertani plates supplemented with $10 \mu \mathrm{g} / \mathrm{ml}$ thymine (LBthy). Viable colonies were counted following overnight incubation at $37^{\circ} \mathrm{C}$.

\section{DNA Accumulation}

Overnight cultures were diluted 1:100 and grown in LB medium supplemented with $0.1 \mu \mathrm{Ci}$ / $\mathrm{ml}$ of $\left[{ }^{3} \mathrm{H}\right]$ thymine and $10 \mu \mathrm{g} / \mathrm{ml}$ of thymine to an $\mathrm{OD}_{600}$ of 0.3 , at which time half of the culture was treated with $10 \mathrm{mM}$ hydrogen peroxide for $5 \mathrm{~min}$, while the other half was mock treated. The cells in each culture were then collected on Fisher brand $0.45-\mu \mathrm{m}$ general membrane filters and resuspended in pre-warmed LB medium supplemented with $0.1 \mu \mathrm{Ci}$ / $\mathrm{ml}$ of $\left[{ }^{3} \mathrm{H}\right]$ thymine and $10 \mu \mathrm{g} / \mathrm{ml}$ of thymine. At the times indicated, duplicate $0.5-\mathrm{ml}$ aliquots of culture were lysed and the DNA was precipitated in cold 5\% trichloroacetic acid (TCA) and filtered onto Millipore glass fiber filters. The amount of ${ }^{3} \mathrm{H}$ on each filter was determined by scintillation counting. 


\section{Glycosylase Repair Assay}

Overnight cultures were diluted 1:100 and grown in LBthy medium to an $\mathrm{OD}_{600}$ of 0.3 . At this time, the cultures were treated with $10 \mathrm{mM}$ hydrogen peroxide for $5 \mathrm{~min}$. The cells were then filtered onto a $0.45-\mu \mathrm{m}$ membrane and resuspended in pre-warmed LBthy medium. At the times indicated, a $0.75-\mathrm{ml}$ aliquot of culture was transferred to an equal volume of icecold NET (100 mM NaCl, $10 \mathrm{mM}$ Tris, pH 8.0, $20 \mathrm{mM}$ EDTA, pH 8.0), centrifuged for 60 sec, resuspended in $140-\mu \mathrm{L}$ lysis buffer $(1 \mathrm{mg} / \mathrm{ml}$ lysozyme, $0.5 \mathrm{mg} / \mathrm{ml} \mathrm{RNase} \mathrm{A} \mathrm{in} 10 \mathrm{mM}$ Tris, $1 \mathrm{mM}$ EDTA, pH 8.0), and incubated at $37^{\circ} \mathrm{C}$ for $15 \mathrm{~min} .10 \mu \mathrm{L}$ of $10 \mathrm{mg} / \mathrm{ml}$ proteinase $\mathrm{K}$ and $10 \mu \mathrm{l}$ of $20 \%$ Sarkosyl were then added to the samples and incubation continued for a further $30 \mathrm{~min}$ at $37^{\circ} \mathrm{C}$. Samples were then extracted with four volumes of $\mathrm{phenol/chloroform/isoamyl} \mathrm{alcohol} \mathrm{(25:24:1),} \mathrm{followed} \mathrm{by} \mathrm{four} \mathrm{volumes} \mathrm{of} \mathrm{chloroform/}$ isoamyl alcohol (24:1) and then dialyzed against $200 \mathrm{ml}$ of $0.1 \times$ TE for $45 \mathrm{~min}$ using $47-\mathrm{mm}$ Whatman $0.05-\mu \mathrm{m}$ pore disks. $15-\mu \mathrm{l}$ of each DNA sample was then treated in reaction buffer (30 mM EDTA, pH 8.0, $22.5 \mathrm{mM} \mathrm{NaCl}, 5 \mathrm{mM}$ Tris, pH 8.0) supplemented with either no enzyme, $0.53 \mu \mathrm{M}$ Fpg glycosylase, or $2.7 \mu \mathrm{M}$ Endo III for $1 \mathrm{hr}$ at $37^{\circ} \mathrm{C}$. Enzyme preparations were titrated using purified undamaged genomic DNA as a template. For Fpg, the highest enzyme concentration which did not exhibit nonspecific activity on the undamaged DNA was used, which corresponded to $0.53 \mu \mathrm{M}$. In the case of Endo III, nonspecific activity was not observed, even at the highest concentration examined (Fig S1).

Treated samples were then electrophoresed on a $0.5 \%$ alkaline agarose gel in $30 \mathrm{mM} \mathrm{NaOH}$, $1 \mathrm{mM}$ EDTA at $30 \mathrm{~V}$ for $16 \mathrm{~h}$, stained and visualized with ethidium bromide.

\section{Quantification of lesion-free DNA fragments}

The intensity of each high molecular weight band was determined using ImageQuant software (GE Healthcare). The fraction of lesion-free DNA fragments was quantified as a ratio of high molecular weight DNA in the glycosylase-treated band to the band with no glycosylase treatment at each time point. To normalize for any nicks or AP sites present in the DNA before hydrogen peroxide exposure, the ratio at each time point was divided by the ratio at the pre-hydrogen peroxide treatment time point, resulting in the following formula: $\left(\mathrm{Gly}_{\mathrm{T}} / \mathrm{NG}_{\mathrm{T}}\right) / \mathrm{R}_{0}$, where Gly $\mathrm{y}_{\mathrm{T}}$ is the band intensity for glycosylase treated DNA at time, $\mathrm{T}$. $\mathrm{NG}_{\mathrm{T}}$ is the band intensity for DNA with no glycosylase treatment at time, T. $\mathrm{R}_{0}$ is $\left(\mathrm{Gly}_{\mathrm{T}} /\right.$ $\mathrm{NG}_{\mathrm{T}}$ ) at the time immediately preceding the addition of hydrogen peroxide.

\section{Supplementary Material}

Refer to Web version on PubMed Central for supplementary material.

\section{Acknowledgments}

We thank Z. Hatahet for generously providing Fpg and Endo III. This work was funded by an American Heart Association Predoctoral Fellowship, 09PRE2090004, to BJS, and an NIH/NIEHS Exploratory Research Grant, 1R21ES018940-1

\section{Citations}

1. Wallace SS. Biological consequences of free radical-damaged DNA bases. Free Radic Biol Med. 2002; 33:1-14. [PubMed: 12086677]

2. Ide H, Petrullo LA, Hatahet Z, Wallace SS. Processing of DNA base damage by DNA polymerases. Dihydrothymine and beta-ureidoisobutyric acid as models for instructive and noninstructive lesions. J Biol Chem. 1991; 266:1469-1477. [PubMed: 1988431] 
3. Evans J, Maccabee M, Hatahet Z, Courcelle J, Bockrath R, Ide H, Wallace S. Thymine ring saturation and fragmentation products: lesion bypass, misinsertion and implications for mutagenesis. Mutat Res. 1993; 299:147-156. [PubMed: 7683083]

4. Efrati E, Tocco G, Eritja R, Wilson SH, Goodman MF. "Action-at-a-distance” mutagenesis. 8oxo-7, 8-dihydro-2'-deoxyguanosine causes base substitution errors at neighboring template sites when copied by DNA polymerase beta. J Biol Chem. 1999; 274:15920-15926. [PubMed: 10336498]

5. Wallace SS. DNA damages processed by base excision repair: biological consequences. Int J Radiat Biol. 1994; 66:579-589. [PubMed: 7983450]

6. Krokan HE, Standal R, Slupphaug G. DNA glycosylases in the base excision repair of DNA. Biochem J. 1997; 325:1-16. [PubMed: 9224623]

7. Laspia MF, Wallace SS. Excision repair of thymine glycols, urea residues, and apurinic sites in Escherichia coli. J Bacteriol. 1988; 170:3359-3366. [PubMed: 2457010]

8. Blaisdell JO, Hatahet Z, Wallace SS. A novel role for Escherichia coli endonuclease VIII in prevention of spontaneous G-->T transversions. J Bacteriol. 1999; 181:6396-6402. [PubMed: 10515930]

9. Parsons JL, Elder RH. DNA N-glycosylase deficient mice: a tale of redundancy. Mutat Res. 2003; 531:165-175. [PubMed: 14637253]

10. Saito Y, Uraki F, Nakajima S, Asaeda A, Ono K, Kubo K, Yamamoto K. Characterization of endonuclease III (nth) and endonuclease VIII (nei) mutants of Escherichia coli K-12. J Bacteriol. 1997; 179:3783-3785. [PubMed: 9171430]

11. Boiteux S, Gajewski E, Laval J, Dizdaroglu M. Substrate specificity of the Escherichia coli Fpg protein (formamidopyrimidine-DNA glycosylase): excision of purine lesions in DNA produced by ionizing radiation or photosensitization. Biochemistry. 1992; 31:106-110. [PubMed: 1731864]

12. Dizdaroglu M, Laval J, Boiteux S. Substrate specificity of the Escherichia coli endonuclease III: excision of thymine- and cytosine-derived lesions in DNA produced by radiation-generated free radicals. Biochemistry. 1993; 32:12105-12111. [PubMed: 8218289]

13. Park EM, Shigenaga MK, Degan P, Korn TS, Kitzler JW, Wehr CM, Kolachana P, Ames BN. Assay of excised oxidative DNA lesions: isolation of 8-oxoguanine and its nucleoside derivatives from biological fluids with a monoclonal antibody column. Proc Natl Acad Sci U S A. 1992; 89:3375-3379. [PubMed: 1565629]

14. Cathcart R, Schwiers E, Saul RL, Ames BN. Thymine glycol and thymidine glycol in human and rat urine: a possible assay for oxidative DNA damage. Proc Natl Acad Sci U S A. 1984; 81:56335637. [PubMed: 6592579]

15. Cabrera M, Nghiem Y, Miller JH. mutM, a second mutator locus in Escherichia coli that generates G.C----T.A transversions. J Bacteriol. 1988; 170:5405-5407. [PubMed: 3053667]

16. Chetsanga CJ, Lindahl T. Release of 7-methylguanine residues whose imidazole rings have been opened from damaged DNA by a DNA glycosylase from Escherichia coli. Nucleic Acids Res. 1979; 6:3673-3684. [PubMed: 386277]

17. Chetsanga CJ, Lozon M, Makaroff C, Savage L. Purification and characterization of Escherichia coli formamidopyrimidine-DNA glycosylase that excises damaged 7-methylguanine from deoxyribonucleic acid. Biochemistry. 1981; 20:5201-5207. [PubMed: 7028101]

18. Tchou J, Kasai H, Shibutani S, Chung MH, Laval J, Grollman AP, Nishimura S. 8-oxoguanine (8hydroxyguanine) DNA glycosylase and its substrate specificity. Proc Natl Acad Sci U S A. 1991; 88:4690-4694. [PubMed: 2052552]

19. Hatahet Z, Kow YW, Purmal AA, Cunningham RP, Wallace SS. New substrates for old enzymes. 5-Hydroxy-2'-deoxycytidine and 5-hydroxy-2'-deoxyuridine are substrates for Escherichia coli endonuclease III and formamidopyrimidine DNA N-glycosylase, while 5-hydroxy-2'-deoxyuridine is a substrate for uracil DNA N-glycosylase. J Biol Chem. 1994; 269:18814-18820. [PubMed: 8034633]

20. D'Ham C, Romieu A, Jaquinod M, Gasparutto D, Cadet J. Excision of 5,6-dihydroxy-5,6dihydrothymine, 5,6-dihydrothymine, and 5-hydroxycytosine from defined sequence oligonucleotides by Escherichia coli endonuclease III and Fpg proteins: kinetic and mechanistic aspects. Biochemistry. 1999; 38:3335-3344. [PubMed: 10079077] 
21. Purmal AA, Lampman GW, Bond JP, Hatahet Z, Wallace SS. Enzymatic processing of uracil glycol, a major oxidative product of DNA cytosine. J Biol Chem. 1998; 273:10026-10035.

[PubMed: 9545349]

22. Radman M. An endonuclease from Escherichia coli that introduces single polynucleotide chain scissions in ultraviolet-irradiated DNA. J Biol Chem. 1976; 251:1438-1445. [PubMed: 3498]

23. Dizdaroglu M, Bauche C, Rodriguez H, Laval J. Novel substrates of Escherichia coli nth protein and its kinetics for excision of modified bases from DNA damaged by free radicals. Biochemistry. 2000; 39:5586-5592. [PubMed: 10820032]

24. Hazra TK, Muller JG, Manuel RC, Burrows CJ, Lloyd RS, Mitra S. Repair of hydantoins, one electron oxidation product of 8-oxoguanine, by DNA glycosylases of Escherichia coli. Nucleic Acids Res. 2001; 29:1967-1974. [PubMed: 11328881]

25. Wiederholt CJ, Patro JN, Jiang YL, Haraguchi K, Greenberg MM. Excision of formamidopyrimidine lesions by endonucleases III and VIII is not a major DNA repair pathway in Escherichia coli. Nucleic Acids Res. 2005; 33:3331-3338. [PubMed: 15944451]

26. Schneider JE, Price S, Maidt L, Gutteridge JM, Floyd RA. Methylene blue plus light mediates 8hydroxy 2'-deoxyguanosine formation in DNA preferentially over strand breakage. Nucleic Acids Res. 1990; 18:631-635. [PubMed: 2155406]

27. Dizdaroglu M, Holwitt E, Hagan MP, Blakely WF. Formation of cytosine glycol and 5,6dihydroxycytosine in deoxyribonucleic acid on treatment with osmium tetroxide. Biochem J. 1986; 235:531-536. [PubMed: 3741404]

28. Thayer MM, Ahern H, Xing D, Cunningham RP, Tainer JA. Novel DNA binding motifs in the DNA repair enzyme endonuclease III crystal structure. EMBO J. 1995; 14:4108-4120. [PubMed: 7664751]

29. Bhagwat M, Gerlt JA. 3'- and 5'-strand cleavage reactions catalyzed by the Fpg protein from Escherichia coli occur via successive beta- and delta-elimination mechanisms, respectively. Biochemistry. 1996; 35:659-665. [PubMed: 8555240]

30. Tamm C, Shapiro HS, Lipshitz R, Chargaff E. Distribution density of nucleotides within a desoxyribonucleic acid chain. J Biol Chem. 1953; 203:673-688. [PubMed: 13084637]

31. Marnett LJ. Lipid peroxidation-DNA damage by malondialdehyde. Mutat Res. 1999; 424:83-95. [PubMed: 10064852]

32. Chung FL, Chen HJ, Nath RG. Lipid peroxidation as a potential endogenous source for the formation of exocyclic DNA adducts. Carcinogenesis. 1996; 17:2105-2111. [PubMed: 8895475]

33. Blakely WF, Fuciarelli AF, Wegher BJ, Dizdaroglu M. Hydrogen peroxide-induced base damage in deoxyribonucleic acid. Radiat Res. 1990; 121:338-343. [PubMed: 2315450]

34. Melamede RJ, Hatahet Z, Kow YW, Ide H, Wallace SS. Isolation and characterization of endonuclease VIII from Escherichia coli. Biochemistry. 1994; 33:1255-1264. [PubMed: 8110759]

35. Jiang D, Hatahet Z, Melamede RJ, Kow YW, Wallace SS. Characterization of Escherichia coli endonuclease VIII. J Biol Chem. 1997; 272:32230-32239. [PubMed: 9405426]

36. Jiang D, Hatahet Z, Blaisdell JO, Melamede RJ, Wallace SS. Escherichia coli endonuclease VIII: cloning, sequencing, and overexpression of the nei structural gene and characterization of nei and nei nth mutants. J Bacteriol. 1997; 179:3773-3782. [PubMed: 9171429]

37. Kow YW, Wallace SS, Van Houten B. UvrABC nuclease complex repairs thymine glycol, an oxidative DNA base damage. Mutat Res. 1990; 235:147-156. [PubMed: 2407949]

38. Lin JJ, Sancar A. A new mechanism for repairing oxidative damage to DNA: (A)BC excinuclease removes AP sites and thymine glycols from DNA. Biochemistry. 1989; 28:7979-7984. [PubMed: 2690930]

39. Ide H, Kow YW, Wallace SS. Thymine glycols and urea residues in M13 DNA constitute replicative blocks in vitro. Nucleic Acids Res. 1985; 13:8035-8052. [PubMed: 3906566]

40. Asad NR, de Almeida CE, Asad LM, Felzenszwalb I, Leitao AC. Fpg and UvrA proteins participate in the repair of DNA lesions induced by hydrogen peroxide in low iron level in Escherichia coli. Biochimie. 1995; 77:262-264. [PubMed: 8589055]

41. Karakaya A, Jaruga P, Bohr VA, Grollman AP, Dizdaroglu M. Kinetics of excision of purine lesions from DNA by Escherichia coli Fpg protein. Nucleic Acids Res. 1997; 25:474-479. [PubMed: 9016584] 
42. Ide H, Kotera M. Human DNA glycosylases involved in the repair of oxidatively damaged DNA. Biol Pharm Bull. 2004; 27:480-485. [PubMed: 15056851]

43. Takao M, Kanno S, Kobayashi K, Zhang QM, Yonei S, van der Horst GT, Yasui A. A back-up glycosylase in Nth1 knock-out mice is a functional Nei (endonuclease VIII) homologue. J Biol Chem. 2002; 277:42205-42213. [PubMed: 12200441]

44. Hazra TK, Hill JW, Izumi T, Mitra S. Multiple DNA glycosylases for repair of 8-oxoguanine and their potential in vivo functions. Prog Nucleic Acid Res Mol Biol. 2001; 68:193-205. [PubMed: 11554297]

45. Mudrak SV, Welz-Voegele C, Jinks-Robertson S. The polymerase eta translesion synthesis DNA polymerase acts independently of the mismatch repair system to limit mutagenesis caused by 7,8 dihydro-8-oxoguanine in yeast. Mol Cell Biol. 2009; 29:5316-5326. [PubMed: 19635811]

46. Eoff RL, Stafford JB, Szekely J, Rizzo CJ, Egli M, Guengerich FP, Marnett LJ. Structural and functional analysis of Sulfolobus solfataricus Y-family DNA polymerase Dpo4-catalyzed bypass of the malondialdehyde-deoxyguanosine adduct. Biochemistry. 2009; 48:7079-7088. [PubMed: 19492857]

47. Lee DH, Pfeifer GP. Translesion synthesis of 7,8-dihydro-8-oxo-2'-deoxyguanosine by DNA polymerase eta in vivo. Mutat Res. 2008; 641:19-26. [PubMed: 18359049]

48. Kusumoto R, Masutani C, Iwai S, Hanaoka F. Translesion synthesis by human DNA polymerase eta across thymine glycol lesions. Biochemistry. 2002; 41:6090-6099. [PubMed: 11994004]

49. Courcelle CT, Belle JJ, Courcelle J. Nucleotide excision repair or polymerase V-mediated lesion bypass can act to restore UV-arrested replication forks in Escherichia coli. J Bacteriol. 2005; 187:6953-6961. [PubMed: 16199565]

50. Courcelle CT, Chow KH, Casey A, Courcelle J. Nascent DNA processing by RecJ favors lesion repair over translesion synthesis at arrested replication forks in Escherichia coli. Proc Natl Acad Sci U S A. 2006; 103:9154-9159. [PubMed: 16754873]

51. Kato T, Shinoura Y. Isolation and characterization of mutants of Escherichia coli deficient in induction of mutations by ultraviolet light. Mol Gen Genet. 1977; 156:121-131. [PubMed: 340898]

52. Wagner J, Etienne H, Janel-Bintz R, Fuchs RP. Genetics of mutagenesis in E. coli: various combinations of translesion polymerases (Pol II, IV and V) deal with lesion/sequence context diversity. DNA Repair (Amst). 2002; 1:159-167. [PubMed: 12509262]

53. Mellon I, Hanawalt PC. Induction of the Escherichia coli lactose operon selectively increases repair of its transcribed DNA strand. Nature. 1989; 342:95-98. [PubMed: 2554145]

54. Courcelle J, Carswell-Crumpton C, Hanawalt PC. recF and recR are required for the resumption of replication at DNA replication forks in Escherichia coli. Proc Natl Acad Sci U S A. 1997; 94:3714-3719. [PubMed: 9108043]

55. Courcelle J, Crowley DJ, Hanawalt PC. Recovery of DNA replication in UV-irradiated Escherichia coli requires both excision repair and recF protein function. J Bacteriol. 1999; 181:916-922. [PubMed: 9922256]

56. Yu D, Ellis HM, Lee EC, Jenkins NA, Copeland NG, Court DL. An efficient recombination system for chromosome engineering in Escherichia coli. Proc Natl Acad Sci U S A. 2000; 97:5978-5983. [PubMed: 10811905]

\section{Abbreviations}

$\begin{array}{ll}\text { 5-OHC } & \text { 5-hydroxy cytosine } \\ \text { 5-OHU } & \text { 5-hydroxy uracil } \\ \text { AP sites } & \text { apurinic or apyrimidinic sites } \\ \text { BER } & \text { base excision repair } \\ \text { Fapy-Gua } & \text { 2,6-diamino-4-hydroxy-5-formamidopyrimidine } \\ \text { Fapy-Ade } & \text { 4,6-diamino-5-formamidopyrimidine }\end{array}$




$\begin{array}{ll}\text { Fapy } & \text { formamidopyrimidine } \\ \text { Fpg } & \text { Formamidopyrimidine-N-glycosylase } \\ \text { Endo III } & \text { Endonuclease III } \\ \text { Endo VIII } & \text { Endonuclease VIII }\end{array}$


<smiles>Nc1ncnc(N)c1NC=O</smiles>

Fapy-Ade $(30 \%)^{a}$<smiles>Nc1nc2[nH]c(=O)[nH]c2c(=O)[nH]1</smiles>

8-oxoGuanine $(20 \%)^{a}$ Oxidized Purines<smiles>NC1=NC(NC=O)C(=O)C(N)=N1</smiles>

Fapy-Gua $(10 \%)^{a}$<smiles>CC1(O)C(=O)NC(=O)NC1O</smiles>

Thymine glycol (30\%) Oxidized Pyrimidines<smiles>NC1=NC(=O)NC(O)C1(O)O</smiles>

Cytosine glycol $(5 \%)^{a}$

Figure 1. The structure and relative abundance of some common forms of oxidized base adducts in H2O2-treated cultures

a Approximate frequency of lesions based on treatment with increasing concentrations of hydrogen peroxide. 33 


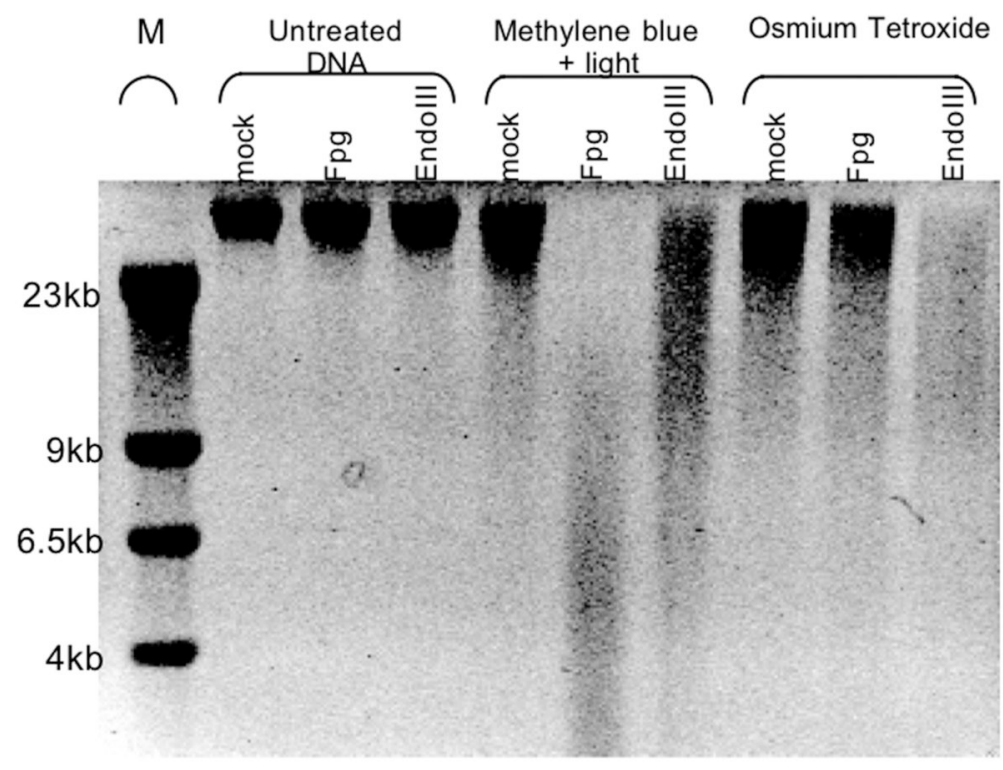

Figure 2. In vitro, the substrate specificity of Fpg and Endo III partially overlap. However, Fpg is more active at 8-oxoguanines and Endo III is more active at thymine glycols Purified high molecular weight DNA containing no lesions, oxidized purines (methylene blue + light treated), or oxidized pyridines (osmium tetroxide treated) was incubated for $1 \mathrm{hr}$ in the presence of no glycosylase, Fpg glycosylase, or Endo III as indicated and analyzed by alkali-agarose gel electrophoresis. The presence of DNA lesions that are recognized by either Fpg or Endo III is indicated by the loss of high molecular weight DNA fragments in those samples. Lane M - lambda HindIII size marker; Fpg - Fpg glycosylase; EndoIII - Endo III glycosylase. 

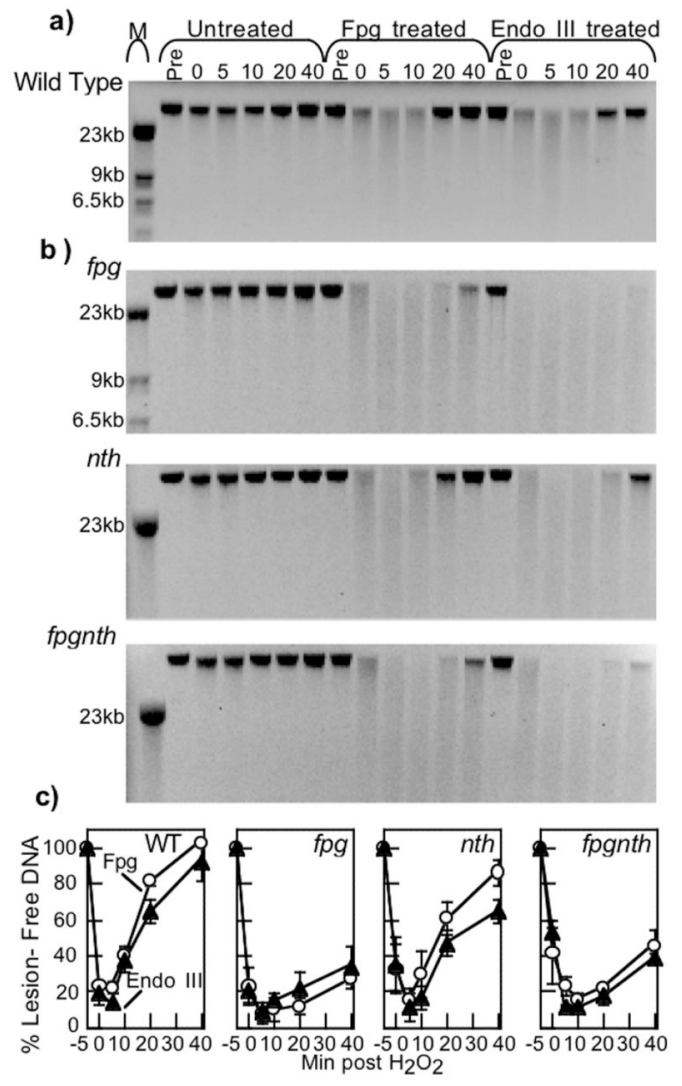

Figure 3. Fpg is required to rapidly remove oxidized purines and pyrimidines from the global genome in vivo

A) Lesions recognized by Fpg and Endo III are rapidly repaired from wild-type cultures in vivo. Cultures were exposed to $10 \mathrm{mM}$ hydrogen peroxide for $5 \mathrm{~min}$ and allowed to recover. At the times indicated, genomic DNA was purified, incubated for $1 \mathrm{hr}$ in the presence of no glycosylase, Fpg, or Endo III, then analyzed by alkali-agarose gel electrophoresis. The loss of high molecular weight DNA fragments following glycosylase treatment indicates the presence of Fpg- or Endo III-recognized lesions in the DNA. Lane M - lambda HindIII size marker. B) Fpg is required to rapidly remove both Fpg- and Endo III-recognized lesions from the E. coli genome. Cultures of fpg and $n t h$ mutants were treated and analyzed as in (A). C) The percent lesion-free, high molecular weight DNA in Fpg- (open circles) and Endo III-treated (filled triangle) samples is plotted at each time point relative to mocktreated samples. All plots represent an average of three independent experiments. Error bars represent the standard error of the mean. 

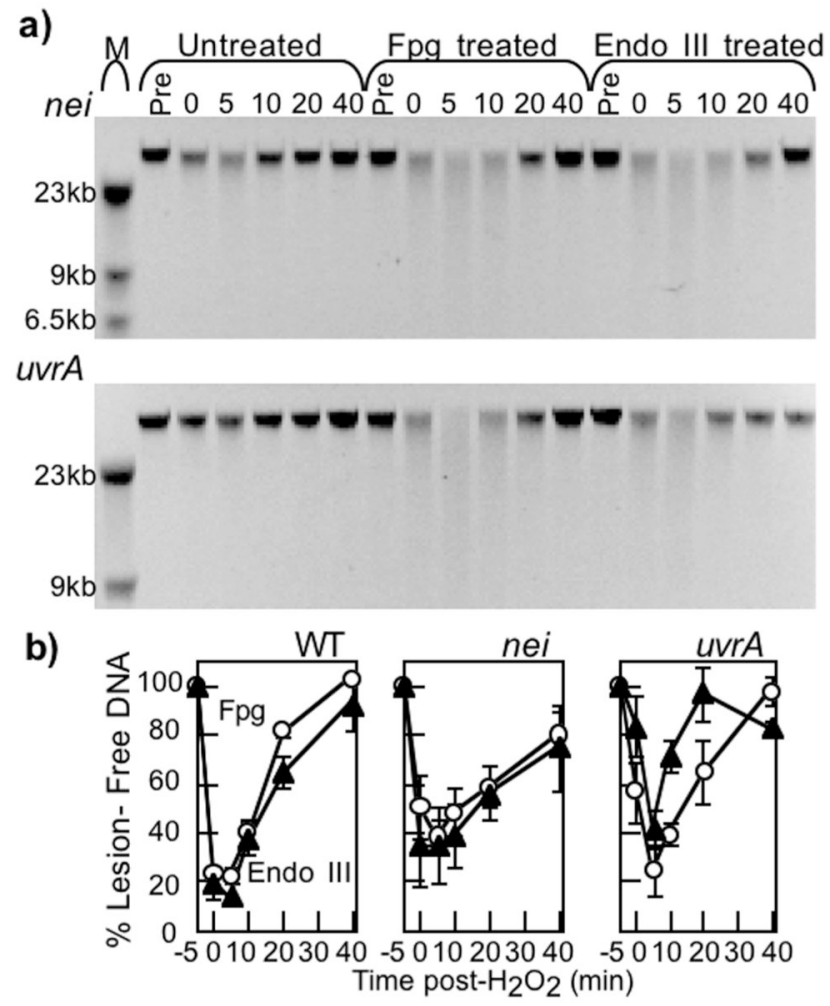

Figure 4. Endo VIII and nucleotide excision repair do not significantly contribute to the removal of 8-oxoguanine or thymine glycol lesions from the overall genome

A) nei (upper panel) and $u v r A$ (lower panel) cultures were exposed to $10 \mathrm{mM}$ hydrogen peroxide for $5 \mathrm{~min}$ and allowed to recover. At the times indicated, genomic DNA was purified, incubated for $1 \mathrm{hr}$ in the presence of no glycosylase, Fpg, or Endo III, then analyzed by alkali-agarose gel electrophoresis. Lane M - lambda HindIII size marker. B) The percent of lesion-free, high molecular weight DNA in Fpg- (open circles) and Endo IIItreated (filled triangle) samples is plotted at each time point relative to mock-treated samples. All plots represent an average of three independent experiments. Error bars represent the standard error of the mean. 


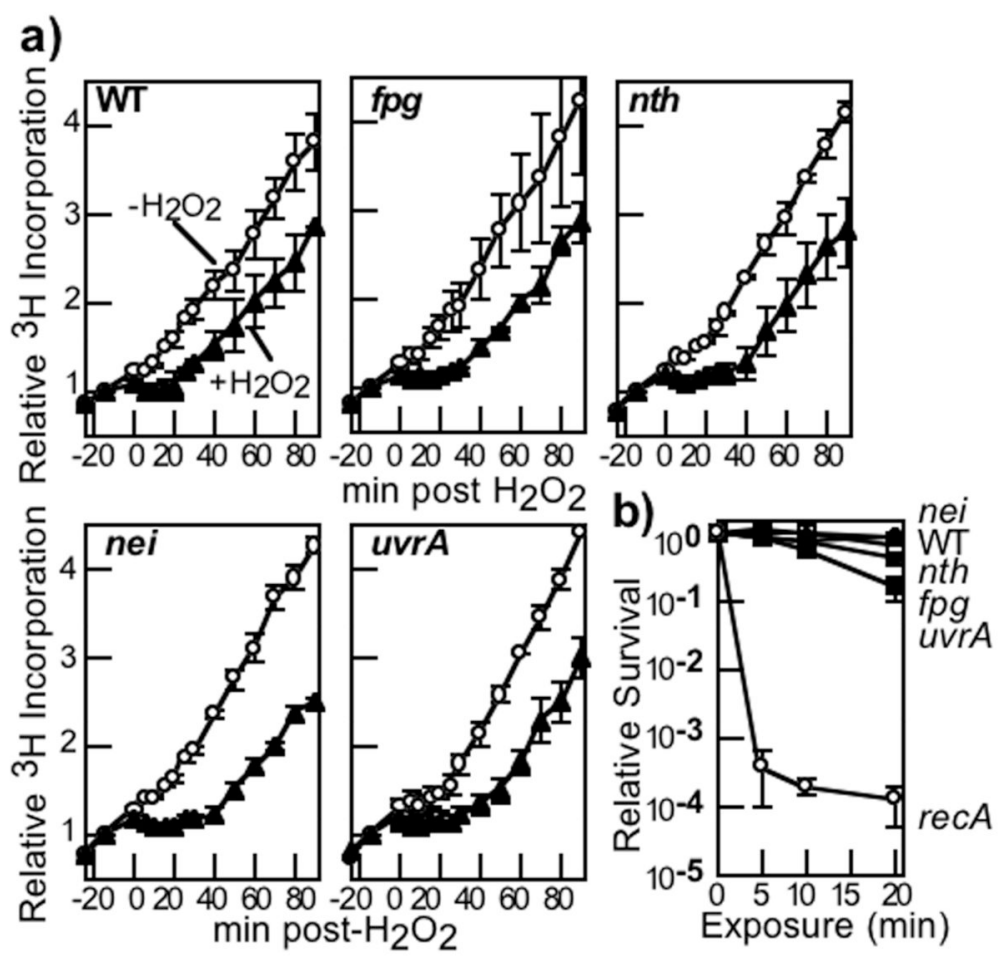

Figure 5. The absence of Fpg, Endo III, Endo VIII or nucleotide excision repair does not prevent DNA synthesis from resuming following hydrogen peroxide-induced DNA damage

A) Cultures grown in the presence of ${ }^{3} \mathrm{H}$-thymine were exposed to hydrogen peroxide for 5 min (open circles) or mock-treated (filled triangles), resuspended in fresh $37^{\circ} \mathrm{C}$ medium and allowed to recover. The relative amount of ${ }^{3} \mathrm{H}$-thymine incorporated into the DNA is plotted over time. All plots represent an average of two independent experiments. Error bars represent the standard error of the mean. The amount of ${ }^{3} \mathrm{H}$ in each sample at time 0 was between 7000 and $13000 \mathrm{cpm}$ for all experiments. B) Cells lacking DNA glycosylases or nucleotide excision repair are not hyper-sensitive to hydrogen peroxide. The survival of each strain following exposure to $10 \mathrm{mM}$ hydrogen peroxide for the indicated time period is plotted. Strains: wild-type (open square), $\Delta f p g$ (CL1009, filled circle), $\Delta n e i$ (CL 1005, filled diamond), $\Delta n t h$ (CL1006, filled triangle), $\Delta u v r A$ (CL21, filled square), and $\Delta r e c A$ (CL002, open circle). Plots represent an average of three independent experiments. Error bars represent the standard error of the mean. 
Bacterial strains used

Table 1

\begin{tabular}{|c|c|c|}
\hline Strain & Relevant genotype & Source \\
\hline SR108 & wild type & Mellon \& Hanawalt ${ }^{53}$ \\
\hline CL002 & recA::Tn10 & Courcelle et al ${ }^{54}$ \\
\hline CL021 & $u v r A:: \operatorname{Tn} 10$ & Courcelle et al ${ }^{55}$ \\
\hline CL1005 & nei: $: c a m$ & P1 from SW2-8 ${ }^{36}$ \\
\hline CL1006 & $n t h: k a n$ & P1 from BW402 in SR108 ${ }^{36}$ \\
\hline CL1009 & fpg::amp & P1 from SW2-F into SR $108^{8}$ \\
\hline DY351 & $\Delta$ lacU169, gal490, $\Delta$ cl857, $\Delta$ (cro-bioA), $\Delta$ (kil-git::Cm) & Yu et al 2000 PNAS $^{56}$ \\
\hline CL1775 & $f p g:$ tet $\Delta$ lacU169, gal490, $\Delta$ cl857, $\Delta$ (cro-bioA), $\Delta$ (kil-git::Cm) & DY351 $\times$ PCR (fpgF-fpgR primers) \\
\hline CL1778 & fpg::tet & P1 from CL1775 into SR108 \\
\hline CL1938 & fpg::tet nth::kan & P1 from CL1778 into CL1006 \\
\hline
\end{tabular}

